\title{
DIAZEPAM IN PULMONARY SURGERY
}

\author{
Jean-Paul Dechêne, M.D., AND Roland Deshosiers, M.D. ${ }^{*}$
}

Diazeram is a derivative of benzodiazopine which has attracted the interest of anaesthetists since its introduction in 1961. Its sedative effect is intermediate between the neuroleptics and the tranquilizers which are often useful in anaesthesia, and we have studied its usefulness in patients undergoing pulmonary surgery.

Our observations will be presented as a comparative study of two series of cases, in one of which diazepam was used (54 cases), and in the other of which a standard premedication was used with thiopentone induction for anaesthesia for pulmonary surgery ( 56 cases).

\section{METHODS}

The patients were selected at random. There were 35 cases of pulmonary tuberculosis (diazepam 18, thiopentone 17), 68 cases of cancer (diazepam 34, thiopentone 34 ), and 7 cases of bronchiectasis (diazepam 2, thiopentone 5), making a total of 110 patients. These patients differed in age, sex, weight, pathology, and anaesthetic risk, and required different types of surgery.

Although the patients were chosen at random, irrespective of the nature of the operation and the pathology, a strict procedure was followed in evaluating the anaesthetic risk (according to the classification of the American Society of Anesthesiologists), while making the observations and during the administration of the anaesthetic.

\section{Procedure}

The blood pressure was measured by indirect stethoscopy, controlled occasionally by direct readings and recordings on an electrosphygmomanometer. The heart rate and ECG were observed and recorded on an oscilloscope and electrocardiograph. The tidal ventilation was monitored by a Wright respirometer. Finally, the blood pressure and heart rate before and after the induction of anaesthesia were accurately compared.

The anaesthetic techniques were as follows:

1. Premedication. Either (a) our standard premedication with oral Noludar, (\$) secobarbital, or Tuinal ${ }^{\circledR}$ (with or without diphenhydramine or promethazine) the night before, and meperidine or aneleridine, diphenydramine (Benadryl) and atropine intramuscularly one hour before induction, or (b) premedication with diazepam ( $p e r$ os and intramuscular).

2. Induction of anaesthesia with intravenous thiopentone or diazepam.

-Department of Anaesthesia and Resuscitation, Hospital Laval, Quebec City. 
3. Anaesthesia maintained with halothane, and succinylcholine as required for muscular relaxation.

4. Pulmonary ventilation controlled with a Bird-type respirator, in association with a Vernitrol anaesthetic apparatus and a double lumen catheter (Carlens or White-Carlens).

\section{Results}

The results are presented in the form of tables. Table I shows the mean ages and weights of the two groups of patients, while Tables II and III indicate the distribution of anaesthetic risks in these two groups and the respective dosages of diazepam and thiopentone. It can be seen from Table II that there were no "moribund" patients (category 5) and that patients who received diazepam included a greater number of "bad risks" (categories 3 and 4).

TABLE I

\begin{tabular}{|c|c|c|c|c|c|c|}
\hline \multirow[b]{2}{*}{ Drug } & \multicolumn{2}{|c|}{ Number of patients } & \multicolumn{2}{|c|}{ Age (yrs) } & \multicolumn{2}{|c|}{ Weight (lbs) } \\
\hline & male female & total & mean & range & mean & range \\
\hline Valium & 15 & 54 & 45.9 & $17-69$ & 135.7 & $85-260$ \\
\hline Thiopentone & 10 & 56 & 49.7 & $16-74$ & $135 . \overline{5}$ & $90-205$ \\
\hline
\end{tabular}

TABLE II

\begin{tabular}{lcccc}
\multicolumn{7}{c}{ ANAESTHESIA RISK } \\
\hline & I & II & III & IV \\
\hline Valium & 11 & 20 & 15 & 8 \\
Thiopentone & 19 & 22 & 13 & 2 \\
\hline
\end{tabular}

TABLE III

INDUCTION DOSE

\begin{tabular}{lccr}
\hline & Dosage (mean) & Range & $\mathrm{mg} / \mathrm{kg}$ \\
\hline Valium & 28.1 & $20-60$ & .46 \\
Thiopentone & 433.8 & $140-625$ & 7.11 \\
\hline
\end{tabular}

Table IV illustrates the changes in arterial pressure in our patients. Those receiving diazepam showed no significant modification of the blood pressure, either systolic or diastolic. On the other hand, the patients who were given thiopentone suffered a sharp fall in pressure, which was statistically highly significant.

The spirometric data given in Table $\mathrm{V}$ indicate a marked difference between the two groups; there was only a slight diminution of the tidal volume with diazepam, in contrast to an almost complete apnoea with thiopentone. 
TABLE IV

BLOOD PRESSURE

(mm $\mathrm{Hg}$ with $95 \%$ confidence limits)

\begin{tabular}{lccccc}
\hline \hline & \multicolumn{2}{c}{ Before induction } & & \multicolumn{2}{c}{ After induction } \\
\cline { 2 - 3 } \cline { 5 - 6 } & systolic & diastolic & & systolic & diastolic \\
\hline Valium & $117.2 \pm 3.24$ & $75.3 \pm 1.97$ & & $113.0 \pm 2.99$ & $74.1 \pm 2.61$ \\
Thiopentone & $121.9 \pm 3.84$ & $78.3 \pm 2.13$ & & $97.1 \pm 2.54$ & $69.4 \pm 1.50$ \\
\hline
\end{tabular}

TABLE V

Stirometer Readings

(with $95 \%$ confidence limits)

\begin{tabular}{lcr}
\hline & Before induction & \multicolumn{1}{c}{ After induction } \\
\hline Valium & $524.4 \pm 32.95$ & $482.9 \pm 38.28$ \\
Thiopentone & $559.8 \pm 24.4$ & $42.4 \pm 33.34$ \\
\hline
\end{tabular}

TABLE VI

Pulse

(with $95 \%$ confidence limits)

\begin{tabular}{lcc}
\hline \hline & Before induction & After induction \\
\hline Valium & $89.5 \pm 2.72$ & $88.9 \pm 2.97$ \\
Thiopentone & $87.5 \pm 2.32$ & $75.8 \pm 2.96$ \\
\hline
\end{tabular}

TABLE VII

Anaesthetist's Subjective Impression of Patient

\begin{tabular}{lccc}
\hline & Before induction & After induction & Postop. \\
\hline Valium & & & \\
$\quad$ excellent & 42 & 52 & 29 \\
good & 12 & - & 23 \\
$\quad$ fair & & & 2 \\
Thiopentone & 16 & -22 & 3 \\
$\quad$ excellent & 39 & 2 & 76 \\
good & 1 & & \\
\hline
\end{tabular}

Changes in pulse rate are shown in Table VI. There was no important modification with diazepam, but thiopentone was associated with a significant bradycardia.

Table VII presents some data on the anaesthetist's subjective impression of the patient's condition. From this table it is clear that $(a)$ diazepam gives superior premedication, as reported previously; $(b)$ after induction of anaesthesia with diazepam, there is a total absence of significant repercussions on vital signs, in contrast to what happens with thiopentone; $(c)$ the patients in the diazepam 
group have a better postoperative recovery, judged by the following criteria: excellent - no complications; good - only minor complications, e.g. prolonged sleep; fair - complications, with cardiorespiratory difficulties, e.g. cardiac arrest.

\section{Discussion}

\section{General comments}

Analgesic properties. Like the barbiturates, diazepam is not an analgesic. Hence analgesics are absolutely essential during painful surgery.

Cardiorespiratory effects. Diazepam causes only a minor fall in blood pressure if given in a moderate dose and injected slowly. There is usually a slight bradycardia, relieved by premedication with atropine. Unlike the barbiturates, diazepam does not produce bronchorrhea, muscarinic effects, or bronchospasm; this makes it particularly valuable for the pulmonary or bronchitic patient.

Intravenous injections of diazepam are well tolerated but it is preferable to administer it into the infusion tubing to avoid pain.

Muscular relaxation. The use of diazepam did not reduce the requirements for relaxant drugs.

\section{Comments specific to pulmonary surgery}

The high versatility of this new intravenous anaesthetic medication is indicated by its successful use when dealing with tuberculosis, carcinoma, and bronchiectasis. In pulmonary surgery three properties of diazepam are of particular interest to the anaesthetist:

1. The absence of muscarinic effects, bronchospasm, and bronchorrhea is especially appreciated in bronchoscopy and other endoscopic procedures (intubation with cuffed tube, insertion of a tube with double lumen) which precede anaesthesia for pulmonary surgery.

2. Diazepam greatly facilitates inhalation anaesthesia, which we believe is the method of choice for pulmonary surgery.

3. The frequency of atelectasis is reduced. None of our cases showed atelectasis in the first 48 hours.

\section{Summary and Conclusions}

Diazepam compared to thiopentone gives a greatly improved intravenous induction; it is thus a new and important pharmacological contribution in our search for an ideal anaesthetic technique for pulmonary surgery.

\section{RÉSUMÉ}

Il s'agit d'une étude comparative de deux séries de cas, l'une comportant l'utilisation du diazepam, l'autre l'utilisation d'une médication classique en anesthésie pour chirurgie pulmonaire re cancérologie, tuberculose, bronchiectasie.

Durant les périodes pré-, per-, et post-opératoires, des observations et des études sont faites sur la fonction respiratoire et sur la fonction cardio-vasculaire (tension artérielle, électro-cardiogramme, spirométrie et observations constantes 
des signes vitaux) et ces études sont rapportées dans la présente communication.

La conclusion de cette étude et de ces observations nous permet de reconnaître statistiquement parlant que l'utilisation du diazepam en anesthésie pour chirurgie pulmonaire a contribué pour beaucoup à l'obtention d'une technique d'anesthésie "optima" en chirurgie pulmonaire.

\section{ACKNOWLEDGMENTS}

We wish to thank Hoffmann-La Roche Laboratories, who made this work possible.

\section{BIBLIOGRAPHY}

Blondeau, P. Diazepam et Anesthesia Generale. Cahiers Anesth. 13: 207, 213 (1965).

Brandt, A. L. \& OAKes, F. D. Preanaesthesia Medication: Double-blind Study of a New Drug, Diazepam. Anaesth. Analg. 44: 125 (1965).

Campan, L. \& Espano, M.-Th. Note sur le diazepam en anesthesiologie. Ann. anesthesiol. Franc, 5: 711 (1964).

Corditer, A.; Goyette, M.; Ké́ri-Szántó, M.; \& Rheault, J. A Comparison of the Action of Meperidine and Diazepam in Anaesthetic Premedication. Canad. Anaesth. Soc. J. 13: 368 (1966).

Dechêne, Jean-Paul. Diazepam et Anesthesia-Reanimation. Laval Medical. 38 (April 1967).

Marrubine, B. \& Tretola, L. Diazepam as a Preoperative Tranquilizer in Neuro-anaesthesia: A Preliminary Note. Brit. J. Anaesth. 38: 934 (1965).

MAspoli, M. Le Valium: Son action sur la respiration. Schewiz. med. Wschr. 97: 320 (1967).

McClish, A.; Andrew, D.; \& Tetreault, L. Intravenous Diazepam for Psychiatric Reaction Following Open-heart Surgery. Canad. Anaesth. Soc. J. 15: 63 (1968).

MCCuish, A. Diazepam as an Intravenous Induction Agent for General Anaesthesia. Canad. Anaesth. Soc. J. 13: 562 (1966).

SADove, M. S. et al. Effects of Chlordiazepoxide and Diazepam on the Influence of Meperidine on the Respiratory Response to Carbon Dioxide. J. New Drugs. 5 (March/April 1965).

Steen, S. N.; Weitzner, S. W.; Amaka, K.; \& Martinez, L. R. The Effects of Diazepam on the Respiratory Response to Carbon Dioxide. Canad. Anaesth. Soc. J. 13: 374 (1966).

Stovner, J. \& ENDRESEN, R. Diazepam in Intravenous Anaesthesia. Lancet. 2: 1298 (1965).

Tornetta, F. J. Diazepam as Preanaesthetic Medication: A Double-blind Study. Anaesth. \& Analg. 44: 449 (1965). 